\section{Opinion versus scientific consensus}

I was deeply troubled by the content of "The dangers of scientific consensus" by Peter Geddes in the June issue of Frontiers (2005). The author attempts to use selected snippets from the history of science to call into question our scientific knowledge of global warming, and to raise doubts about the need for immediate action. He throws in an irrelevant zinger about science versus homecoming queens, raises the problem of "activists" (used here in the ecological rather than in the judicial sense), and even obliquely attempts to taint rational global change science with the specter of Stalin-era Lysenkoism! Geddes' letter is recycled from his 2004 newspaper article (www.freeeco.org/articleDisplay.php?id=425); it is an opinion piece, and not a legitimate scientific comment.

Geddes' gambit is not a new one, and I urge readers of Frontiers to read Edmondson (1991) for an example of how anti-environmental propaganda was used in an attempt to prevent completely rational efforts to control the flow of 20 million gallons per day of sewage into Lake Washington, Seattle. Two sentences from a letter written by the leader of the King County Taxpayer's League (p 26) are especially relevant because they present a familiar mantra of complete denial mixed with an equally familiar admonition that still further research must be performed prior to acting: "Indeed, we are rather surprised that you have been able to make a hypothesis to the effect that there is pollution in the Lake. Such a hypothesis which of its very nature is most doubtful, no doubt, might be the starting point for a real scientific survey of the question of ascertaining whether or not there is pollution in Lake Washington and how it can be eliminated."

Fortunately, objective science prevailed over skeptical, uninformed opinion and anti-environmental rhetoric; the citizens of Seattle voted to restore the lake, based on the best available knowledge at that time. There were indeed some initial economic costs involved, but the longterm benefits have been much greater, and Lake Washington has proved to be one of the best examples of a highly successful marriage between rational science, thoughtful policy, and concerned public action.

We are now faced with even greater pollution problems, that will have effects at a global rather than a regional scale. Thankfully, realistic and pragmatic leaders among the G8 nations, scientists from the US National Academy of Sciences and ten other national academies, as well as many of our Nation's governors, including conservative Republican Governor Arnold Schwartzenegger of California, have already correctly concluded that our current knowledge of atmospheric and climatic science amply justifies beginning to act now to restrict global emissions of greenhouse gases.

\section{Val H Smith}

Dept of Ecology and Evolutionary

Biology

University of Kansas

Lawrence, KS

Edmondson WT. 1991. The uses of ecology: Lake Washington and beyond. Seattle, WA: University of Washington Press.

Geddes P. 2005. The dangers of scientific consensus. Front Ecol Environ 5: 242.

I'm seriously concerned that the letter from Peter Geddes that appeared in the June issue of Frontiers (see reference above) was accepted for publication. In his letter, Geddes challenges an important policy issue arising out of conclusions solidly based on scientific evidence, and seeks to alter readers' opinions. However, he does not present a single item of scientific evidence negating the accumulated evidence (eg Cox et al. 2000) that global warming is happening at an unprecedented rate, and that human activities are at least partly to blame.

$\mathrm{He}$ opposes actions to reduce

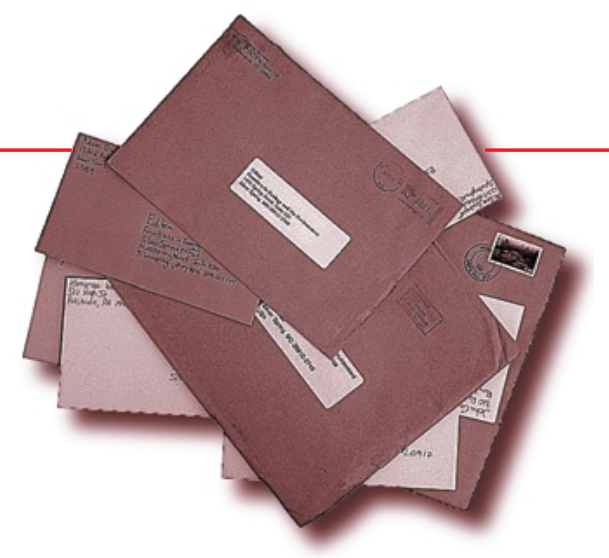

greenhouse gas emissions, and attempts to make two points. The first of these is that "While most unlikely in the climate change debate, scientific 'consensus' may be overturned by a single experiment." His second point is that: "Policy controversies involve trade-offs among competing values. Responsible policy makers know that environmental quality is only one of several important and competing values."

Similar arguments must have been made in 1955 , by those opposing the large cost of diverting sewage input from surrounding communities to Lake Washington, in metropolitan Seattle. The successful effort to restore the lake as a beautiful recreational resource was sparked by limnological research by Edmondson (1970), relating the appearance of the cyanobacterium Oscillatoria in other lakes to subsequent eutrophication. Geddes erroneously equates scientific consensus, which is based on review of the relevant evidence to "appeals based on authority", citing as an example the Catholic Church's condemnation of those who "did not subscribe to their preferred model of the Universe".

He justifies his second point by claiming that environmental quality is only one of several important and competing values. I am reminded of an essay by a chapter chair of the Washington Native Plant Society, who wrote of meeting a county councilman who said he viewed her as a hobbyist, one of several special interest "user groups". She wondered whether he was aware that he, too, belonged to a special interest user group - the "breathers". Geddes continues his argument by reference to "the Russian experience under 
Lysenko" whose "pseudo-scientific theories of plant genetics were used to justify creating the 'New Soviet Man'." I'll leave the reader to consider the effect that such a comparison, appearing in a publication of what is probably the world's largest ecological society, might have on opinion makers.

Geddes concludes: "We should resist being stampeded into public policies with huge immediate costs and few, if any, benefits." He fails to specify the "huge immediate costs" of adopting such policies. The benefits would include the creation of new industry and employment that would develop and build alternative energy sources and products with lower energy demand, reducing dependence on imports of energy, as well as a reduction of the rate at which natural plant and animal communities change, and at which crop production is impacted because of changes in climate and water availability.

Geddes is executive vice president of the Foundation for Research on Economics and the Environment. A web search of the foundation and of its sponsors led me to believe that its purpose is to influence public opinion, promoting the view that scientific conclusions regarding man's effects on our environment are to be ignored when the policies and earnings of corporations might be negatively affected.

\section{Michael Marsh}

Seattle, WA

swamp@blarg.net

Cox PM, Betts RA, Jones CD, et al. 2000. Acceleration of global warming due to carbon-cycle feedbacks in a coupled climate model. Nature 408: 184-87.

Edmondson WT. 1970. Phosphorus, nitrogen, and algae in Lake Washington after diversion of sewage. Science 169: 690-91.

Peter Geddes makes two important points in his June 2005 Write Back commentary. The first is that a single experiment could overturn an accepted idea at any time. However, he allows this worthy idea to lead him into the trap of the Great American Syllogism: "All men are created equal. Everyone is entitled to an opinion. Therefore all opinions are equal.” In arenas where the theory and data are so complex that few people can synthesize new analyses, we rely on experts in fields outside our own. With regard to the topic of global warming, which Geddes raises, I am, at least for now, more comfortable accepting the views of "a majority of climate scientists, including 99 Nobel Prize winners" than I am of, for instance, a non-scientist (Monbiot 2005) who claims that global warming is a "cult-theme"(LaRouche 1997).

Geddes states that science is not like a popularity contest, and to a point this is true. But a homecoming queen (or any elected person, as we well know) can win by a tiny percentage, or even a single vote - very different from the vast consensus versus the lone outsider scenario Geddes promotes. Also, once elected, the winner is in office until the next election. Science functions more like a parimutuel betting system, where each of the players continually re-evaluates the odds as new information comes in. Sure, everyone at the track is entitled to an opinion, but the lone outsider almost always goes home broke.

Geddes' second point deals with society's values and choices. This point too is well taken. Most would agree that scientific results cannot be the sole basis of policy decisions, and that other factors must be taken into consideration. However, Lysenko, while part of the politically correct consensus, was just the sort of lone outsider in the international genetics community that Geddes says we should heed.

The problem with Geddes' reasoning is that he conflates the two points he makes. It is simply disingenuous to posit that as long as there are any dissenting opinions the question is still open, because a single dissenting voice can always be identified for any topic imaginable (Goodman 2005). If the requirement for action is that there is no dissent, inaction would be the only outcome. Of course, no management program has much chance of success if it is based on faulty or incomplete information. However, in giving as much weight to the poorly supported or misguided opinions of a few individuals as to the consensus achieved by many experts working over many years, we decrease the probability of ever achieving the policy goal.

\section{Bob Kinzie}

Zoology Department

University of Hawaii

Honolulu, $\mathrm{HI}$

Goodman E. 2005. When facts don't fit the opinion. Boston Globe. June 19: op ed.

LaRouche LH Jr. 1997. It is now nine years later. Executive Intelligence Review. Oct 12.

www.larouchepub.com/lar/1997/nine_years_ later.html)

Monbiot G. 2005. Guardian Weekly. May 19. 